УДК 338.24

\title{
ОЦЕНКА ЭФФЕКТИВНОСТИ НАУЧНЫХ ИССЛЕДОВАНИЙ И РАЗРАБОТОК В БЕЛАРУСИ
}

\section{Э. Э. Ермакова ${ }^{1}$, М. П. Мишкова²}

\begin{abstract}
${ }^{1}$ Магистр экономических наук, старший преподаватель кафедры управления, экономики и финансов учреждения образования «Брестский государственный технический университет», Брест, Беларусь, e-mail: ermakova.eleonora@gmail.com

${ }_{2}^{2}$ Магистр экономических наук, старший преподаватель кафедры управления, экономики и финансов учреждения образования «Брестский государственный технический университет», Брест, Беларусь, e-mail: mishkova69@yandex.by
\end{abstract}

\section{Ресрерат}

Эффективность инновационного развития страны выступает производной от повышения конкурентоспособности науки, роста её эффективности. В связи с этим особый интерес представляют исследования в области оценки эффективности финансирования научных исследований и разработок. В статье определены характерные черты понятия эфффективности научно-исследовательской деятельности (НИД), установлены проблемы оценки эффективности НИД, проведён анализ финансирования НИД в Республике Беларусь, дана оценка эффективности затрат на научные исследования.

Ключевые слова: научные исследования, разработки, научно-исследовательская деятельность, затраты, финансирование, эфффективность, анализ.

\section{EVALUATION OF THE RESEARCH EFFECTIVENESS AND DEVELOPMENT IN BELARUS}

\section{Abstract}

\section{E. E. Ermakova, M. P. Mishkova}

The effectiveness of the country's innovative development is a derived from increasing the competitiveness of science, increasing its efficiency. In this regard, research in the field of evaluating the effectiveness of funding for research and development is of particular interest. The article defines the characteristic features of the effectiveness of Research and Development (R\&D), identifies the problems of effectiveness evaluating of R\&D, analyzes the financing of R\&D in the Republic of Belarus, and assesses the effectiveness of research costs.

Keywords: research, development, research activities, costs, financing, efficiency, analysis.

\section{Введение}

Ускоренное научно-техническое развитие страны выступает одним из приоритетных направлений в условиях усиления международной конкуренции. Укрепление научно-технического и инновационного потенциала служит основным ориентиром для стран, которые понимают, что в век науки и высоких технологий основополагающим курсом является инновационное развитие.

Наука в современном мире стала одним из важнейших инструментов обеспечения поступательного экономического развития. Это объясняется как минимум двумя основными обстоятельствами. Во-первых, способность генерировать и внедрять достижения научно-технического прогресса превращается в один из факторов обеспечения конкурентоспособности как национальной экономики в целом в глобальной конкурентной среде, так и отдельных товаропроизводителей на конкретных рынках. Во-вторых, в настоящее время наука сама по себе становится специфической сфрерой товарного производства, которая создает очень дорогостоящий товар - объекты интеллектуальной собственности [1].

Результативность инвестиций в науку имеет прямую зависимость c финансированием научно-исследовательских и опытно-конструкторских работ (НИОКР), однако результаты интеллектуальной деятельности могут быть получены с некоторым временным лагом финансирования, в связи с чем проблема оценки эфффективности финансирования научных исследований достаточно затруднительна. Прямое сопоставление затрат и результатов не даёт корректных итогов, в первую очередь по причине разных временных промежутков между финансированием и получением коммерческих результатов. Как известно, процессу коммерциализации инновации предшествует несколько этапов интеллектуальной деятельности, включая прикладные исследования, разработки и опытное производство. Очевидно, что вложения средств в исследования и разработки не дают быстрой отдачи, эфффективность от вложений проявляется через некоторое время, финансирование научных исследований - это инвестиции в будущее.

Проблема оценки эффективности научных исследований и разработок является одной из ключевых интересов учёных не одно десятилетие. Основу исследований этого направления заложил P. Солоу в середине XX столетия. В модели Солоу в виде производственной функции показано, что основной движущей силой долгосрочного экономического роста является технический прогресс.

Методологические подходы, разработанные в Беларуси, нашли своё отражение в Постановлении Государственного комитета по науке и технологиям Республики Беларусь «Об утверждении Методических рекомендаций по оценке эффективности научных, научно-технических и инновационных разработок и их внедрения». Данная методика представляет несомненный интерес, т. к. позволяет оценить результаты в рамках реализации научно-исследовательских программ и инновационных проектов методами дисконтирования финансовых потоков, экспертных оценок, используя различные критерии. Однако показатели результативности позволяют лишь косвенно определить экономическую эфффективность затрат на научные исследования и разработки, в связи с чем выявление факторов, условий развития науки и количественное измерение результативности научно-технической деятельности остаётся актуальной современной проблемой для исследования.

Понятие результативность в настоящем исследовании используем в широком смысле как синоним эффективности. Классическое экономическое понятие эфффективности в экономической теории трактуется как соотношение между полученными результатами и затратами, произведёнными для достижения этих результатов. Определение же результативности научной деятельности имеет свои особенности. Наука - процесс творческий, оценить её результативность традиционными подходами весьма непросто.

Для оценки влияния результатов научно-технической деятельности на экономическое развитие используем данные официальной статистики. Количественное измерение результатов нововведений характеризуют такие показатели, как число изобретений, количество заключенных лицензионных соглашений на передачу объектов промышленной собственности (ОПС), количество действующих патентов, технологический баланс платежей за использование объектов интеллектуальной собственности (ОИС). Аналитические показатели ряда динамики количественных величин ОПС: по видам ОПС, по уровню технологий, по степени престижности объектов. Качественные оценки, такие как уровень изобретательской активности, коэфффициент технологической зависимости.

Научная новизна исследования состоит в развитии теоретикометодических положений и разработке новых подходов к оценке экономической эффективности научных исследований и разработок.

Проблемы измерения эффективности в научно-исследовательской деятельности

Научно-исследовательская деятельность не направлена прямо на получение экономического эфффекта, особенно если речь идёт о результатах фундаментальной науки. 
Вестник Брестского государственного технического университета. 2021

Фундаментальные исследования направлены на получение новых теоретических знаний, при этом использование новых знаний в практической деятельности ещё не имеет определённого назначения. Результаты фундаментальных исследований не подлежат коммерциализации, а публикуются в научных изданиях.

Для оценки эффективности научной деятельности в области фундаментальных исследований в настоящее время широко используется библиометрический подход, позволяющий оценить вклад учёных и организаций в науку. Результаты фрудаментальной науки измеряют количественными параметрами, используя абсолютные и относительные показатели, рассчитанные на базе количества публикаций и цитирования научных работ.

Методы библиометрии в последние годы подвергаются критике в связи с возможностью искусственного завышения индексов цитирования. Достоверная оценка научной деятельности остаётся актуальной задачей, требующей разработки новых методов на основе существующего инструментария для проведения библиометрического анализа.

Результаты оценки фундаментальных исследований могут быть использованы при определении перспективных научных направлений.

Прикладные исследования направлены на получение новых тех нических решений с целью реализации конкретных практических задач. Другими словами, прикладные исследования направлены на решение проблем использования научных знаний, полученных в результате фундаментальных исследований, в практической деятельности людей При этом результаты фундаментальных исследований могут иметь неопределённый временной характер взаимосвязи с прикладными научно-исследовательскими работами (НИР). Разрыв между технологической инновацией, основанной на результатах фундаментальных исследований, может составлять от нескольких месяцев до десятков лет.

Результатом прикладных исследований в области техники и технологий являются новые технические решения, которые могут иметь промышленное применение, т. е. могут быть использованы для создания новой наукоёмкой продукции, новых технологий.

Разработки направлены на производство новых или усовершенствование существующих продуктов или процессов. Разработки это исследования, которые направлены на внедрение в практику результатов фундаментальных и прикладных исследований.

Результаты исследований и разработок как творческого труда авторов являются объектами интеллектуальной собственности. Соответственно, абсолютные и относительные показатели результатов интеллектуальной деятельности выступают показателями эффективности прикладных исследований и разработок. Однако количество выданных патентов не является совершенной мерой результатов научной деятельности по нескольким причинам. Во-первых, степень новизны, изобретательский уровень и значимость полученных объектов промышленной собственности не одинаков, а некоторые изобретения не патентуются, приобретая статус ноу-хау. Во-вторых, недостаточно перспективные изобретения не имеют потенциала коммерциализации.

Следующий этап предполагает процесс коммерческого использования полученных результатов научно-технической деятельности, который включает освоение интеллектуального продукта и выпуск новой продукции на потребительский рынок, в связи с чем основными экономическими показателями эффективности инвестиций в науку на этом этапе выступает объём наукоёмкой продукции, показатели экспорта высокотехнологичной продукции.

Оценка эффективности инвестиций в науку сталкивается с объективными трудностями технического характера - нехваткой статистических ресурсов. Неполнота статистических данных значительно ограничивает возможности анализа научно-технической деятельности, затрудняет проведение международных сопоставлений, сужает статистические исследования.

\section{Анализ затрат на НИОКР в Беларуси}

Развитие науки и эффективность её функционирования определяют объёмы и источники финансирования. Реальный вклад в науку характеризуют ежегодно учитываемые статистикой показатели затрат на научные исследования и разработки.

Доступные данные, учитываемые официальной статистикой дают возможность детализировать и анализировать показатели внутренних затрат на исследования и разработки, сопоставлять эти данные с показателями других стран и выявлять проблемы.

Финансирование научных исследований и разработок в регионах страны осуществляется неравномерно, что отражается на структуре общих затрат (рисунок 1).
Наука в Беларуси сконцентрирована в Минске, более половины всех затрат на научные исследования и разработки приходится на г. Минск, где они составили в 2019 г. 69,3 \% от общей суммы затрат. Также достаточно велика доля затрат на научные исследования и разработки в Минской области, доля которых составила $16,8 \%$. На третьем месте по уровню затрат на НИР выступает Гомельская область, далее Витебск и Брест. Минимальная доля затрат на научные исследования и разработки наблюдалась в Гродненской области, всего 0,7 \% от общего объёма затрат.

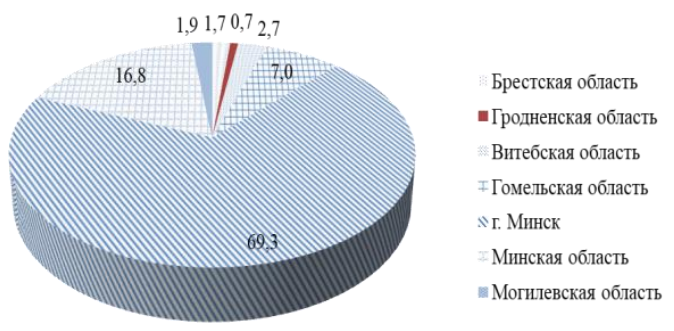

Рисунок 1 - Структура затрат на научные исследования и разработки по регионам Республики Беларусь в 2019 г. [2]

Для корректного сравнения финансирования науки в регионах важным представляется изучение показателей внутренних затрат на исследования и разработки в расчёте на одну научно-исследовательскую организацию. Максимальные значения имеют организации Минской области, сумма затрат в которых на исследования и разработки превышала в 2019 г. среднюю величину общереспубликанских затрат на одну организацию более чем в полтора раза, и в 2016 г. в 1,3 раза. Также велико значение исследуемого показателя в г. Минске, где превышение составляет более $10 \%$. Кроме Минска и Минской области, значение внутренних затрат на исследования и разработки в расчёте на одну научно-исследовательскую организацию превышает среднереспубликанское значение в 2019 г. в Гомельской области на 20 \%. В остальных регионах уровень финансирования научно-исследовательских организаций был ниже средних значений по стране.

Минимальное значение исследуемого показателя наблюдается в Гродненском и Брестском регионах, в 2019 г. его величина была ниже среднереспубликанского значения в 6,4 раза и 4,5 раза соответственно.

В структуре внутренних затрат на исследования и разработки преобладают затраты на технические науки, доля которых составляет 69,5 \%.

Затраты на оплату труда превышают все остальные составляющие затрат на исследования и разработки, их доля составляла в 2019 г. $40 \%$, доля отчислений на социальные нужды - $13 \%$. Что касается доли затрат на приобретение оборудования, то она составила $2,7 \%$ от общих затрат.

Финансирование исследований и разработок осуществляется в Беларуси по основным видам работ: фундаментальные научные исследования, прикладные научные исследования и экспериментальные разработки. Изучая структуру финансирования по этим направлениям, можно отметить, что более половины затрат направляется на экспериментальные разработки, составляя $60 \%$ всех затрат, на фундаментальные исследования при этом приходится $14 \%$.

Настоящая структура финансирования науки вполне оправдана и связана, в первую очередь, с ограниченными возможностями ресурсов.

Основным источником финансирования науки выступает государственный бюджет. Конкретно доля средств государственного бюджета во внутренних затратах на научные исследования и разработки в 2019 г. составила 44,2\%. Собственные средства организаций составили 34 \% от всех затрат, при этом 95 \% этих средств были направлены коммерческими организациями.

В структуре затрат организаций на инновации в 2019 г. преобладали технологические инновации (98,7 \%), основная доля затрат пришлась на приобретение машин и оборудования $(67,4 \%)$, при этом крайне низкой была доля затрат на приобретение новых и высоких технологий 0,03 \%. Необходимость технического перевооружения очевидна в условиях жесткой конкуренции, однако для устойчивого развития экономики необходимо создавать и приобретать новейшие технологии. Вложения средств в приобретение новых технологий дают достаточно быструю отдачу.

Производственное проектирование и подготовка производства для выпуска новых продуктов, внедрения новых услуг занимали в структуре инновационных затрат второе место после затрат на приобретение машин и оборудования. Их доля составила $34,5 \%$. Затраты на научные исследования и разработки составили 2,3 \%. 


\section{Результативность науки}

Результативность прикладной науки и разработок оценим по числу патентов на изобретения и полезные модели, как основных результатов интеллектуальной деятельности.

Тенденция патентования последних десяти лет остаётся неизменной. Начиная с 2011 г. в Беларуси наблюдается падение изобретательской активности, число зарегистрированных объектов промышленной собственности сократилось к 2019 г. в 3,4 раза (рисунок 2).

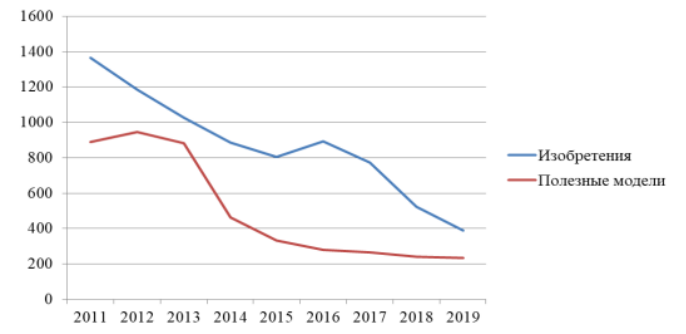

Рисунок 2 - Число выданных патентов национальным заявителям на объекты промышленной собственности [2]

Изобретательская активность характеризует определённую степень распространения и результативности творческой деятельности в сфере технологий. Оценивать уровень изобретательской активности необходимо на основе системы абсолютных и относительных показателей, отражающих результат изобретательской деятельности и охват изобретательской деятельности.

Невозможно утверждать, что снижение патентной активности характеризует недостаточную эффективность бюджетных расходов. Необходим дополнительный анализ факторов, влияющих на результативность изобретательской деятельности. Важной составляющей в первую очередь выступает уровень финансирования науки. Прямая зависимость между объёмом инвестиций в научно-исследовательскую деятельность и патентной деятельностью очевидна.

Программы инновационного развития Республики Беларусь 2016-2020 гг., 2010-2015 гг., предусматривающие доведение показателя наукоёмкости ВВП до уровня $3 \%$, не были выполнены.

Государственная стратегия «Наука и технологии: 2018-2040» предусматривает увеличение инвестиций в исследования и разработки опережающими темпами по сравнению с динамикой ВВП, В том числе через планомерное наращивание наукоёмкости ВВП. Стратегия предусматривает устойчивое обеспечение показателя наукоёмкости ВВП на уровне 3 \% к 2040 г. [3].

Приоритетное финансирование НИР и инновационных проектов при этом будет направлено в первую очередь на развитие и формирование чают информационно-коммуникационные технологии, нанотехнологии, биотехнологии и др. И во-вторых, на прикладные НИОКР, направленные на создание новых технологий, товаров, работ и услуг, являющихся пер-

Важнейшим результирующим индикатором прикладных исследований и разработок выступает торговля технологиями. В целом, в мире права на ОИС занимают всё большую долю в составе активов предприятий, в связи с чем коммерческие сделки передачи прав на лицензионной основе становятся более частыми.

В Беларуси количество договоров о передаче прав на использование объектов промышленной собственности в 2019 г. превысило показатель предыдущего года на 21,5 \%, составив 430 лицензионных договоров.

Количество организаций, приобретающих новые технологии, сократилось в два раза по сравнению с периодом 2012-2015 гг. Десять организаций выступали в качестве лицензиара при передаче новых технологий за пределы Республики Беларусь. Высокие технологии не приобретались и не передавались

Удельный вес отгруженной инновационной продукции в общем объёме продукции в стране последние годы составляет 15-18 \%, продукция, обладающая мировой новизной, составила в 2019 г. 1,6 \% от объёма инновационной продукции.

Результативность затрат на науку можно оценить по конкурентоспособности продукции на внешнем рынке, которая, в свою очередь, может быть оценена с помощью доли экспорта отечественной высокотехнологичной продукции в общем объеме продукции обрабатывающей промышленности.

Доля экспорта наукоёмкой и высокотехнологической продукции в общем объеме экспорта составляет 35,6 \%. Удельный вес экспорта высокотехнологичных секторов национальной экономики, которые вклюспективными с точки зрения потенциального коммерческого эффекта.

высокотехнологичных товаров в общем объеме экспорта товаров и услуг 2,3 \%, наблюдается рост этих показателей.

С 2017 г. статистикой зафиксирован рост производительности труда, индекс которого в 2019 г. составил 101,4. Данный показатель также выступает результатом финансирования НИОКР.

В качестве одного из индикаторов результативности науки выступают также процессы цифровой трансформации экономики, формирующие экономику нового тип и обеспечивающие переход к новому технологическому укладу.

В целом процессы цифровизации в Беларуси охватили все ссреры хозяйствования: промышленность, науку, здравоохранение, финансы, образование, торговлю и др. В международном рейтинге Индекса развития информационно-коммуникационных технологий Беларусь в 2017 г. заняла 32 место, опережая Российскую Федерацию. Доля валовой добавленной стоимости сектора информационно-коммуникационных технологий в ВВП постоянно увеличивается, в 2018 г. её величина составила $5,6 \%$.

\section{Заключение}

Проведённый анализ убедительно подтверждает, что с повышением роли интеллектуальной собственности в экономическом развитии стран и регионов всё шире используют индикаторы интеллектуальной деятельности для мониторинга и оценки эффективности научно-технической и инновационной деятельности [4].

Проведенное исследование позволило определить сущность понятия эффективности научно-исследовательской деятельности, которая заключается в улучшении использования ограниченных ресурсов для получения наилучших результатов.

Несмотря на достаточно серьёзный инновационный потенциал ряда регионов Беларуси, результативность научной деятельности невысока. Очевидно, что основной причиной такого положения является недостаточный уровень финансирования научных исследований и инновационной деятельности.

Увеличение затрат на исследования и разработки может повысить инновационную активность организаций в регионах, а также способствовать технологической модернизации экономики. Но при этом помимо мер финансового характера необходимо применять системные меры, обеспечивающие рациональное реформирование и развитие сектора исследований и разработок.

Кризис стимулирует научно-технический прогресс, заставляет искать новые прогрессивные технологии, позволяющие повысить производительность, снизить издержки и улучшить конкурентные позиции на рынке.

Реализация стратегического инновационного развития Республики Беларусь позволит обеспечить технологическую безопасность и устойчивую положительную динамику развития страны, повысить конкурентоспособность национальной экономики и выйти на новое качество экономического роста.

\section{Список цитированных источников}

1. Колотухин, В. Подходы к оценке эффективности использования научно-технического потенциала / В. Колотухин // Наука и инновации. - 2006. - № 4 (38). - С. 56-58.

2. Наука и инновационная деятельность в Республике Беларусь / Статистический сборник. - Минск, 2020 - 125 с.

3. Стратегия «Наука и технологии: 2018-2040» / Постановление Президиума Национальной академии наук Беларуси № 17 от 26.02.2018.

4. Ермакова, Э. Э. Изобретательская активность в инновационной деятельности / Э. Э. Ермакова // Перспективы развития инвестиционно-строительного комплекса в странах Восточной Европы: сборник научных трудов. - Брест: Изд. БрГТУ, 2016. - С. 79-84.

\section{References}

1. Kolotuhin, V. Podhody k ocenke effektivnosti ispol'zovaniya nauchnotekhnicheskogo potenciala / V. Kolotuhin // Nauka i innovacii. - 2006. № 4 (38). - S. 56-58.

2. Nauka i innovacionnaya deyatel'nost' v Respublike Belarus' / Statisticheskij sbornik. - Minsk, 2020 - $125 \mathrm{~s}$.

3. Strategiya «Nauka i tekhnologii: 2018-2040» / Postanovlenie Prezidiuma Nacio-nal'noj akademii nauk Belarusi № 17 ot 26.02.2018.

4. Ermakova, E. E. Izobretatel'skaya aktivnost' v innovacionnoj deyatel'nosti / E. E. Ermakova // Perspektivy razvitiya investicionno-stroitel'nogo kompleksa v stranah Vostochnoj Evropy: sbornik nauchnyh trudov. Brest: Izd. BrGTU, 2016. - S. 79-84.

Материал поступил в редакцию 21.02.2021 